Tohoku J. Exp. Med., 2009, 218, 149-154

\title{
Daily Intake of Green and Yellow Vegetables Is Effective for Maintaining Bone Mass in Young Women
}

\author{
Hiroko Fujii, ${ }^{1}$ Tsuyako Noda, ${ }^{2}$ Toshimi Sairenchi ${ }^{1}$ and Takashi Muto ${ }^{1}$ \\ ${ }^{1}$ Department of Public Health, Dokkyo Medical University School of Medicine, Shimotsuga, Tochigi, Japan \\ ${ }^{2}$ Department of Food Science, Sagami Women's University, Sagamihara, Kanagawa, Japan
}

\begin{abstract}
The increasing proportion of underweight young women may lead to an increase in those with low bone mass. The present study investigated whether bone mass level is associated with lifestyle factors among young Japanese women. A total of 103 Japanese female college students aged 20-21 majoring in food science participated in this cross-sectional study. We measured bone area ratio at the os calcis using quantitative ultrasound (QUS) and assessed lifestyle factors including diet and physical activity using a selfreported questionnaire. Bone area ratio was defined as a proportion of bone substance in a cross section of os trabeculare. Ninety-one subjects who completed the questionnaire were categorized into two groups according to the average bone area ratio of the 103 subjects $(30.9 \%)$, calculated based on the screening method for osteoporosis prevention: 69 subjects with normal bone mass (bone area ratio: $36.2 \pm 3.8 \%$ ) and 22 subjects with low bone mass (bone area ratio: $28.1 \pm 1.6 \%$ ). In normal group, 12 subjects (17.4\%) had a dietary habit of not daily intake of green and yellow vegetables, such as carrot and spinach, while this occurred in 10 subjects $(45.5 \%)$ in low group $(P=0.007)$. Adjusted logistic regression analyses showed that the subjects without daily intake of green and yellow vegetables had almost 5 -fold risk of low bone mass, compared to the subjects having daily intake of the vegetables [Odds ratio: $4.96(95 \% \mathrm{Cl} 1.36-18.18)$ ]. In conclusion, daily intake of green and yellow vegetables is effective for maintaining bone mass in young women. - Osteoporosis; Bone mass; Vegetables; Young women; Health education.
\end{abstract}

Tohoku J. Exp. Med., 2009, 218 (2), 149-154. (C) 2009 Tohoku University Medical Press

In young women, being underweight is considered one of the determinants of low bone mass (Sawa et al. 2001; Otsuki et al. 2004; Ibuka et al. 2004; Ho and Kung 2005; Yokouchi et al. 2006; Arimatsu et al. 2009). The proportion of young Japanese women, especially those in their 20s, who are underweight, has increased, from $18.6 \%$ in 1987 to $25.2 \%$ in 2007 (Ministry of Health, Labour and Welfare of Japan 2009). The increasing proportion of underweight young women may lead to an increase in those with low bone mass. Lifestyle issues including diet and physical activity are important modifiable factors in the development and maintenance of bone mass (Japan Osteoporosis Foundation 2001).

In previous reports (Sakamoto and Miyoshi 2000; Sawa et al. 2001; Tomita et al. 2004; Ibuka et al. 2004; Otsuki et al. 2004; Yokouchi et al. 2006), the bone mass level has been shown to be related to various lifestyle factors in young adults. A correlation between intake of green and yellow vegetables and bone mineral density measured by dual X-ray absorptiometry (DXA) has been reported in young adults (Otsuki et al. 2004). It is important to show the relationship between the bone mass level and dietary pattern on a personal basis as one of the health education methods for maintaining bone mass at a normal level. While DXA is the gold standard for measuring bone mass level, its usefulness as a heath examination is limited because it requires X-ray exposure, lacks portability and has a high cost. Measurement of bone mass level by quantitative ultrasound (QUS) may be better accepted than DXA for routine health check-ups, because it is safer, portable and is relatively inexpensive.

Thus, the present study investigated whether bone mass level measured by QUS is associated with lifestyle factors including diet, especially consumption of green and yellow vegetables, and physical activity in young Japanese women.

Methods
Study design and participants
A total of 108 Japanese female college students aged 20-21 who
majored in food science were enrolled in a cross-sectional study.
Written informed consent was obtained from all subjects, but 5 sub-
jects ( $0.9 \%)$ did not participate in the measurement. Finally bone
mass levels of 103 subjects were measured. Ultimately we used data

Received March 27, 2009; revision accepted for publication April 29, 2009.

*The work was carried out at Sagami Women's University.

Correspondence: Hiroko Fujii, Department of Public Health, Dokkyo Medical University School of Medicine, 880 Kitakobayashi, Mibu,

Shimotsuga, Tochigi, 321-0293, Japan.

e-mail: h-fujii@dokkyomed.ac.jp 
from 91 subjects who completed the questions regarding food frequency. The study protocol was approved by the ethical committee at Sagami Women's University. This study was conducted in the middle of January 2006.

\section{Measurements}

Bone mass level of the os calsis was measured with QUS using the BENUS version 3 ultrasound bone densitometer (Ishikawa Seisakusyo, Japan). The BENUS version 3 measures bone area ratio, a measure of the intraosteal velocity of sound in the os calsis. Bone area ratio is constructed by a computer-assisted graphic representation of the trabecular structure of the bone of the os calsis (Kagechika et al. 1996). It was determined as a proportion of bone substance in a cross section of os trabeculare and its measure was shown as percent (Kagechika et al. 1996). The short-term precision error in vivo was $1.6 \%$ coefficient of variation for bone area ratio in the laboratory (Kagechika et al. 1996). The utility of the bone area ratio was evaluated in comparison with bone mineral density by dual X-ray absorptiometry, which was regarded as the gold standard; bone area ratio of the os calcis was positively and highly correlated with bone mineral density of the lumbar vertebral bodies in the anterolateral projection $(r=0.77)$ and in the lateral projection $(r=0.68)$ in women (Kagechika et al. 1996). In this study, we treated bone area ratio as the bone mass level.

Ninety-one subjects were divided into two groups according to the bone area ratio of $30.9 \%$, which was calculated as a standard value in this study. It was the average bone area ratio of 103 subjects who were measured bone mass level, multiplied by 0.9 , based on the screening method for osteoporosis prevention (Japan osteoporosis foundation 2001): $34.3 \% \times 0.9$. Thus, the normal group was defined as those with $30.9 \%$ or over and the low group was defined as those with less than $30.9 \%$. Finally, the normal group included 69 subjects and the low group included 22 subjects.

The participants were surveyed using a self-reported questionnaire regarding physical state and present lifestyle factors. The items regarding physical state included height, weight and age at menarche. The items of lifestyle factors included food frequencies (dairy products, soybean products, green and yellow vegetables, etc.), dietary habits, and physical activities. Green and yellow vegetables was defined as a category of $\beta$-carotene rich vegetables, such as carrot, spinach, sweet pepper, tomato and pumpkin (Ministry of Health, Labour and Welfare of Japan 2001).

Physical activity level was based on three items; frequency of intense exercise, time spent on exercise each day, and time spent walking each day. Intense exercise was defined as heavy sport or competition, e.g. tennis, jogging, etc. and other exercise was defined as moderate sport or competition, e.g. brisk walking, stretching, etc. An inactive physical activity level was defined as frequency of intense exercise $\leq 1$ time per month, walking time $\leq 1$ hour per day, and exercise time $\leq 30$ minutes per day. Dietary habits included frequency of consuming three daily meals per week, frequency of eating breakfast per week, current dieting, history of dieting, and habitual drinking. Current dieting, history of dieting, and habitual drinking were categorized as yes or no. Categories of food frequency were indicated as follows: three times a day, twice a day, once a day, almost three times a week and less than two times a week. The alternatives for these questions were dichotomized, and subjects were categorized into two grades based on each lifestyle factor.

Body mass index (BMI) was calculated as weight $(\mathrm{kg})$ divided by height squared $\left(\mathrm{m}^{2}\right)$. A BMI $<19 \mathrm{~kg} / \mathrm{m}^{2}$ was defined as underweight for an osteoporosis risk based on the recommended criterion for bone scan in the guidelines set by the World Health Organization (Genant et al. 1999).

\section{Statistical analysis}

Mean and SD were calculated to characterize continuous variables. Significance of differences between the low group and the normal group were determined by unpaired Student's $t$-tests for continuous variables and by Chi-squared test or Fisher's exact test for categorical variables. Logistic regression analysis was used to investigate the probability of being in the low group versus the normal group and odds ratios were calculated with a $95 \%$ confidence interval. Next, BMI category was entered into the regression model, and multiple logistic regression analysis was performed. For all tests, a value of $P<0.05$ was considered significant. All analyses were performed using the SPSS 15.0J for Windows (SPSS Inc., Tokyo, Japan).

\section{Results}

Table 1 shows the comparison of characteristics between the low group and the normal group divided by the bone area ratio. The mean bone area ratio was $28.1 \pm 1.6 \%$ in the low group and $36.2 \pm 3.8 \%$ in the normal group. The proportion of subjects who reported their weight was $65.9 \%$ (60/91). In the normal group, 12 of 69 subjects (17.4\%) had a dietary habit of not daily intake of green and yellow vegetables, such as carrot and spinach, while this occurred in 10 of 22 subjects $(45.5 \%)$ in the low group $(P=0.007)$.

Table 2 shows the odds ratio for risk of being in the low group for bone area ratio by lifestyle factors. The result of multiple logistic regression analysis adjusted for BMI and age at menarche showed that the subjects not having dairy intake of green and yellow vegetables had almost 5 -fold risk of being in the low group compared to the subjects having dairy intake of green and yellow vegetables (Odds ratio: 4.96 (95\%CI 1.36-18.18)).

\section{Discussion}

To our knowledge, this is the first study suggesting that daily intake of green and yellow vegetables is related to bone mass level measured by QUS in young women. It is assumed that the relationship measured by QUS, that is considered be better accepted for routine health check-ups, indicates the importance of underling food intake in health education to prevent osteoporosis. Several studies have reported on bone mass level and food intake among young women (Sawa et al. 2001; Tomita et al. 2004; Otsuki et al. 2004; Ueno et al. 2005; Prynne et al. 2006), but the report of a positive relationship between bone mass level and the intake of green and yellow vegetables has been limited. Our result is in line with Otsuki's report demonstrating that intake of green and yellow vegetables showed a correlation with bone mineral density that was measured by DXA at the lumbar spine in young adults (Otsuki et al. 2004).

Calcium is one of the main minerals for bone-formation and its abundant supply to bones is essential throughout 
Table 1. Comparison of characteristics between the low group and the normal group divided by bone area ratio.

\begin{tabular}{|c|c|c|c|c|c|c|}
\hline \multicolumn{2}{|l|}{ Items } & \multicolumn{2}{|c|}{$\begin{array}{l}\text { The low group } \\
\left(N^{\mathrm{a}}\right)\end{array}$} & \multicolumn{2}{|c|}{$\begin{array}{l}\text { The normal group } \\
\left(N^{\mathrm{a}}\right)\end{array}$} & $P$ value \\
\hline \multicolumn{2}{|l|}{ Bone area ratio, $\%$, mean \pm S.D. } & 22 & $28.1 \pm 1.6$ & 69 & $36.2 \pm 3.8$ & - \\
\hline \multicolumn{2}{|c|}{ Age at menarche, years, mean \pm S.D. } & 20 & $12.6 \pm 1.5$ & 67 & $12.1 \pm 1.5$ & $0.171^{\mathrm{b}}$ \\
\hline \multicolumn{2}{|l|}{ Height, $\mathrm{cm}$, mean \pm S.D. } & 20 & $157.5 \pm 4.4$ & 58 & $159.1 \pm 5.5$ & $0.173^{\mathrm{b}}$ \\
\hline \multicolumn{2}{|l|}{ Weight, $\mathrm{kg}$, mean \pm S.D. } & 17 & $48.8 \pm 5.1$ & 43 & $51.6 \pm 6.9$ & $0.134^{\mathrm{b}}$ \\
\hline \multicolumn{2}{|c|}{ Body mass index, $\mathrm{kg} / \mathrm{m}^{2}$, mean \pm S.D. } & 17 & $19.7 \pm 2.0$ & 43 & $20.3 \pm 2.4$ & $0.333^{\mathrm{b}}$ \\
\hline Body mass index, $\%$ & $<19.0$ & 17 & 35.3 & 43 & 32.6 & $0.839^{\mathrm{c}}$ \\
\hline Current Smorker, \% & yes & 20 & 0 & 61 & 0 & - \\
\hline \multicolumn{7}{|l|}{ Food frequencies, $\%$} \\
\hline Cereals & $<3$ times/day & 22 & 22.7 & 69 & 31.9 & $0.413^{\mathrm{c}}$ \\
\hline Soybean products & $<1$ time/day & 22 & 63.6 & 69 & 56.5 & $0.556^{\mathrm{c}}$ \\
\hline Fish and shellfish & $<1$ time/day & 22 & 72.7 & 69 & 66.7 & $0.595^{\mathrm{c}}$ \\
\hline Dairy products & $<1$ time/day & 22 & 50.0 & 69 & 50.7 & $0.953^{\mathrm{c}}$ \\
\hline Green and yellow vegetables & $<1$ time/day & 22 & 45.5 & 69 & 17.4 & $0.007^{\mathrm{c}}$ \\
\hline Other vegetables & $<1$ time/day & 22 & 31.8 & 69 & 13.0 & $0.044^{\mathrm{c}}$ \\
\hline Fruits & $<1$ time/day & 22 & 77.3 & 69 & 71.0 & $0.567^{\mathrm{c}}$ \\
\hline \multicolumn{7}{|l|}{ Dietary habits, $\%$} \\
\hline Taking three dairy meals & $<6$ days/week & 20 & 15.0 & 61 & 19.7 & $0.751^{\mathrm{d}}$ \\
\hline Eating breakfast & $<6$ days/week & 20 & 10.0 & 61 & 21.3 & $0.336^{\mathrm{d}}$ \\
\hline Habitual drinker & yes & 19 & 42.1 & 61 & 41.0 & $0.931^{\mathrm{c}}$ \\
\hline Current dieting & yes & 20 & 35.0 & 61 & 16.4 & $0.076^{\mathrm{c}}$ \\
\hline History of dieting & yes & 21 & 60.0 & 69 & 55.7 & $0.738^{\mathrm{c}}$ \\
\hline \multicolumn{7}{|l|}{ Physical activity, \% } \\
\hline Intense exercise frequency & $\leq 1$ time/month & 20 & 80.0 & 56 & 83.9 & $0.734^{\mathrm{d}}$ \\
\hline Walking time & $\leq 1$ hour/day & 20 & 90.0 & 56 & 85.7 & $1.000^{\mathrm{d}}$ \\
\hline Exercise time & $\leq 30$ minutes/day & 20 & 70.0 & 56 & 76.8 & $0.547^{\mathrm{c}}$ \\
\hline Physical activity level ${ }^{\mathrm{e}}$ & inactive & 20 & 70.0 & 56 & 62.5 & $0.547^{\mathrm{c}}$ \\
\hline
\end{tabular}

a. $N$ : Number of respondents.

b. $P$-value was determined by Student's unpaired $t$-test.

c. $P$-value was determined by Chi-squared test.

d. $P$-value was determined by Fisher's exact test.

e. Inactive of physical activity level was defined as frequency of intense exercise $\leq$ once a month, walking time $\leq 1$ hour per day, and exercise time $\leq 30$ minutes per day.

life. In young Japanese women (aged 20-29 y), milk products are the primary source of dietary calcium $(29.0 \%)$, and vegetables are secondary $(14.8 \%)$ (Ministry of Health, Labour and Welfare of Japan 2004). In this study, we found that there was no significant difference between the frequency of dairy intake and the value of bone area ratio in the two groups, so we assume that each subjects' intake of vegetables may be an important source of dietary calcium in addition to that from dairy products. Recent studies have reported several mechanisms by which vegetable intake influence the bone mass level. A higher dietary acid load is induced by greater consumption of a Western diet, leading to increased bone resorption and decreased bone formation by buffering bone minerals (Bushinsky 2001). A diet rich in fruits and vegetables including alkalizing nutrients may inhibit bone resorption (Buclin et al. 2001). Furthermore, fruits and vegetables rich in vitamin $\mathrm{C}$ may have a favorable effect on bone metabolism, such as collagen formation (Kaptoge et al. 2003; Simon et al. 2003).

We had hypothesized that BMI would be a predictor of bone mass level, but the results of our study have not supported that hypothesis. Several studies in young Japanese women have reported a positive relationship between BMI and bone indices (Sawa et al. 2001; Otsuki et al. 2004; Ibuka et al. 2004; Yokouchi et al. 2006). We think that the reason may have been the method of measurement; height and weight for calculating BMI was examined by a selfreported questionnaire. Participants tended not to report their weight; the proportion of those who reported their weight was about $65 \%$ of all subjects. We must take into account the lack of weight data and the validity of selfreported height and weight information in young adults 
Table 2. Odds ratios for risk of being in the low group for bone area ratio by lifestyle factors.

\begin{tabular}{|c|c|c|c|c|}
\hline Lifestyle factors & & & $\begin{array}{c}\text { Unadjusted }^{\mathrm{b}} \\
\text { Odds Ratio }\left(95 \% \mathrm{CI}^{\mathrm{d}}\right)\end{array}$ & $\begin{array}{c}\text { Adjusted }^{\mathrm{c}} \\
\text { Odds Ratio }\left(95 \% \mathrm{CI}^{\mathrm{d}}\right)\end{array}$ \\
\hline \multirow{14}{*}{$\begin{array}{l}\text { Food frequencies } \\
\left(N^{\mathrm{a}}=59\right)\end{array}$} & \multirow[t]{2}{*}{ Cereals } & $\geq 3$ times/day & 1 & 1 \\
\hline & & $<3$ times/day & $0.30(0.06-1.49)$ & $0.24(0.05-1.34)$ \\
\hline & \multirow[t]{2}{*}{ Soybean products } & $\geq 1$ time/day & 1 & 1 \\
\hline & & $<1$ time/day & $1.92(0.59-6.21)$ & $2.33(0.67-8.11)$ \\
\hline & \multirow[t]{2}{*}{ Fish and shellfish } & $\geq 1$ time/day & 1 & 1 \\
\hline & & $<1$ time/day & $1.30(0.38-4.44)$ & $1.60(0.44-5.79)$ \\
\hline & \multirow[t]{2}{*}{ Dairy products } & $\geq 1$ time/day & 1 & 1 \\
\hline & & $<1$ time/day & $1.32(0.41-4.28)$ & $1.22(0.36-4.11)$ \\
\hline & \multirow[t]{2}{*}{ Green and yellow vegetables } & $\geq 1$ time/day & 1 & 1 \\
\hline & & $<1$ time/day & $5.14(1.44-18.33)^{*}$ & $4.96(1.36-18.18)^{*}$ \\
\hline & \multirow[t]{2}{*}{ Other vegetables } & $\geq 1$ time/day & 1 & 1 \\
\hline & & $<1$ time/day & $2.80(0.72-10.97)$ & $2.61(0.65-10.49)$ \\
\hline & \multirow[t]{2}{*}{ Fruits } & $\geq 1$ time/day & 1 & 1 \\
\hline & & $<1$ time/day & $1.30(0.35-4.80)$ & $1.98(0.45-8.61)$ \\
\hline \multirow{10}{*}{$\begin{array}{l}\text { Dietary habits } \\
\left(N^{\mathrm{a}}=59\right)\end{array}$} & \multirow[t]{2}{*}{ Taking three dairy meals } & $\geq 6$ days/week & 1 & 1 \\
\hline & & $<6$ days/week & $0.63(0.12-3.32)$ & $0.69(0.13-3.75)$ \\
\hline & \multirow[t]{2}{*}{ Eating breakfast } & $\geq 6$ days/week & 1 & 1 \\
\hline & & $<6$ days/week & $0.22(0.03-1.88)$ & $0.22(0.03-1.89)$ \\
\hline & \multirow[t]{2}{*}{ Habitual drinker } & no & 1 & 1 \\
\hline & & yes & $1.80(0.55-5.86)$ & $1.63(0.48-5.52)$ \\
\hline & \multirow[t]{2}{*}{ Current dieting } & no & 1 & 1 \\
\hline & & yes & $2.06(0.50-8.53)$ & $2.41(0.54-10.79)$ \\
\hline & \multirow[t]{2}{*}{ History of dieting } & no & 1 & 1 \\
\hline & & yes & $0.87(0.28-2.74)$ & $0.92(0.28-2.98)$ \\
\hline \multirow{8}{*}{$\begin{array}{l}\text { Physical activities } \\
\left(N^{\mathrm{a}}=57\right)\end{array}$} & \multirow[t]{2}{*}{ Intense exercise frequency } & $\geq 1$ time/month & 1 & 1 \\
\hline & & $<1$ time/month & $0.51(0.12-2.14)$ & $0.56(0.13-2.38)$ \\
\hline & \multirow[t]{2}{*}{ Walking time } & $\geq 1$ hour/day & 1 & 1 \\
\hline & & $<1$ hour/day & $1.20(0.22-6.68)$ & $1.07(0.19-6.14)$ \\
\hline & \multirow[t]{2}{*}{ Exercise time } & $\geq 30$ minutes/day & 1 & 1 \\
\hline & & $<30$ minutes/day & $0.62(0.17-2.25)$ & $0.67(0.17-2.64)$ \\
\hline & \multirow[t]{2}{*}{ Physical activity level } & active & 1 & 1 \\
\hline & & inactive & $1.14(0.33-3.94)$ & $1.21(0.34-4.36)$ \\
\hline
\end{tabular}
a. $N$ : Number of respondents.
b. Odds ratio unadjusted was estimated by a logistic regression analysis.
c. Odds ratio adjusted for body mass index and age at menarche was estimated by a multiple logistic regression analysis.
d. $95 \% \mathrm{CI}(95 \%$ confidence interval)
$* P<0.05$

(Kuczmarski et al. 2001; Larsen et al. 2008), when interpreting our results including self-reported weight values.

It is assumed that exercise has beneficial effects on bone mass level throughout life. Yokouchi et al. (2006) found a significantly higher bone mass level in young female college students who have continuously participated in regular physical activity, especially from high school to college, and Hirota et al. (1992) found in a retrospective study of female college students that the bone mass level correlated with past physical activity. Furthermore, Fukuharu et al. (2001) reported a positive link between cur- rent or past exercise habits in premenopausal women and found that positive effects of current exercise on bone mass indices were maintained after adjustment for past exercise habits. Their results supported the effectiveness of exercise begun in adulthood (Fukuharu et al. 2001). In our findings, there was no significant relationship between the bone area ratio as an indication of bone mass level and physical activity. Physical activity was also self-reported and determined as the frequency of various forms of impact exercises, exercising time each day and walking time each day; therefore, the possibility of underreporting or over-reporting cannot be 
ruled out. To clarify the relationship between total physical activity and bone mass level, it is important to examine not only exercise but also physical activities in daily life, e.g. climbing stairs, cleaning, etc.

Our study includes several limitations. First, the method of food intake evaluation examined only the frequency but not the quantity or total intake of calcium and other nutrients such as vitamin D (Ministry of Health, Labour and Welfare of Japan 2005; Kremer et al. 2009), vitamin K (Ministry of Health, Labour and Welfare of Japan 2005; Shea and Booth 2008), and vitamin C (Kaptoge et al. 2003; Simon et al. 2003) that influence calcium metabolism, and the validity and reproducibility of this method were not confirmed. Thus, it must be considered that our results are based on estimated food frequency. Second, the study was designed as a cross-sectional study and we did not know the past food intake of the subjects. However, food intake habits during childhood are significantly related to present tendencies in young women (Tomita et al. 2004). Taking account of that, it may be appropriate to conclude that continuous daily intake of green and yellow vegetables in childhood and adolescence may be related to bone mass level as a young adult. Third, we examined a relatively small number of subjects who were not nationally representative of Japanese women in their early 20s. As most of the subjects were in the normal group, the numbers of subjects in the low group may have been too small to detect a significant difference in lifestyle factors affecting bone mass level. In addition, we thought the subjects were well motivated because they were college students majoring in food science and participated in this study as volunteers. Fourth, we did not examine blood pressure, cholesterol levels and anemic symptoms or other factors such as sleep condition and use of supplements. Such factors would have confounding effects on the results. Conclusions from this study should be generalized with caution because of possible bias, and further research is needed to generalize the findings of this study.

The findings of the present study suggest a positive relationship between bone mass level and daily intake of green and yellow vegetables among Japanese female college students. The finding indicates that the possibility that daily intake of green and yellow vegetables is effective for maintaining bone mass in young women. We assume that the association between green and yellow vegetables and bone mass level measured by QUS indicates the importance of emphasizing nutrition in health education in order to prevent osteoporosis.

\section{Acknowledgments}

We appreciated the staff of Sagami Women's University. The present study was conducted as a joint research between Dokkyo Medical University School of Medicine and Sagami Women's University.

\section{References}

Arimatsu, M., Kitano, T., Kitano, N. \& Futatsuka, M. (2009) Correlation between bone mineral density and body composition in Japanese females aged 18-40 years with low forearm bone mineral density. Environ. Health Prev. Med., 14, 46-51.

Buclin, T., Cosma, M., Appenzeller, M., Jacquet, A.F., Decosterd, L.A., Biollaz, J. \& Burckhardt, P. (2001) Diet acids and alkalis influence calcium retention in bone. Osteoporos. Int., 12, 493-499.

Bushinsky, D.A. (2001) Acid-base imbalance and the skeleton. Eur. J. Nutr., 40, 238-244.

Fukuharu, M., Sato, J., Ohsawa, I., Oshida, Y., Kuriki, K., Shibata, K., Tamagawa, T., Nagaya, T., Fujiwara, N., Tokudome, S. \& Sato, Y. (2001) Effects of lifestyle factors on ultrasonographically determined bone health in Japanese women. Public Health, 115, 146-151.

Genant, H.K., Cooper, C., Poor, G., Reid, I., Ehrlich, G., Kanis, J., Nordin, B.E., Barrett-Connor, E., Black, D., Bonjour, J.P., Dawson-Hughes, B., Delmas, P.D., Dequeker, J., Ragi-Eis, S., Gennari, C., Johnell, O., Johnston, C.C. Jr., Lau, E.M., Liberman, U.A., Lindsay, R., Martin, T.J., Masri, B., Mautalen, C.A., Meunier, P.J. \& Khaltaev, N. (1999) Interim report and recommendations of the World Health Organization TaskForce for Osteoporosis. Osteoporos. Int., 10, 259-264.

Hirota, T., Nara, M., Ohguri, M., Manago, E. \& Hirota, K. (1992) Effect of diet and lifestyle on bone mass in Asian young women. Am. J. Clin. Nutr., 55, 1168-1173.

Ho, A.Y. \& Kung, A.W. (2005) Determinants of peak bone mineral density and bone area in young women. J. Bone Miner. Metab., 23, 470-475.

Ibuka, E., Ohida, T., Miyake, T., Suzuki, K., Motojima, S., Harano, S., Yokoyama, E., Kaneita, Y., Kaneko, A. \& Takeda, F. (2004) Relationships between finding of calcaneal quantitative ultrasound and lifestyle in Japanese college students. Nippon Koshu Eisei Zasshi, 51, 764-773 (In Japanese).

Japan osteoporosis foundation. (2001) Osteoporosis prevention manual second edition. Japan Medical Journal, Tokyo (In Japanese).

Kagechika, K., Sueyoshi, T., Kitaoka, K., Kawakita, S. \& Tomita, K. (1996) Performance evaluation of ultrasound bone densitometry of the os calcis by bone area ratio. Research of New Medical Device, 3, 9-18 (In Japanese).

Kaptoge, S., Welch, A., McTaggart, A., Mulligan, A., Dalzell, N., Day, N.E., Bingham, S., Khaw, K.T. \& Reeve, J. (2003) Effects of dietary nutrients and food groups on bone loss from the proximal femur in men and women in the 7th and 8th decades of age. Osteoporos. Int., 14, 418-428.

Kremer, R., Campbell, P.P., Reinhardt, T. \& Gilsanz, V. (2009) Vitamin D status and its relationship to body fat, final height, and peak bone mass in young women. J. Clin. Endocrinol. Metab., 94, 67-73.

Kuczmarski, M.F., Kuczmarski, R.J. \& Najjar, M. (2001) Effects of age on validity of self-reported height, weight, and body mass index: findings from the Third National Health and Nutrition Examination Survey, 1988-1994. J. Am. Diet. Assoc., 101, 28-34.

Larsen, J.K., Ouwens, M., Engels, R.C., Eisinga, R. \& van Strien, T. (2008) Validity of self-reported weight and height and predictors of weight bias in female college students. Appetite, 50, 386-389.

Ministry of Health, Labour and Welfare of Japan. (2001) Application of Japanese food composition table enlarged fifth edition. (Accessed April 20, 2009 at http://www.mhlw.go.jp/topics/ 0106/tp0628-2.html) (In Japanese).

Ministry of Health, Labour and Welfare of Japan. (2004) The National Health and Nutrition Survey in Japan, 2002. Daiichi Shuppan publishing, Co., Ltd., Tokyo (In Japanese).

Ministry of Health, Labour and Welfare of Japan. (2005) Dietary 
Reference intake for Japanese, 2005. Daiichi Shuppan Publishing Co., Ltd., Tokyo (In Japanese).

Ministry of Health, Labour and Welfare of Japan. (2009) The National Health and Nutrition Survey in Japan, 2007. (Accessed March 15, 2009 at http://www.mhlw.go.jp/houdou/ 2008/12/dl/h1225-5d.pdf) (In Japanese).

Otsuki, T., Sakaguchi, H., Hatta, E., Hatayama, T., Hatada, S., Miura, Y., Takata-Tomokuni, A., Hyodoh, F., Tomomitsu, T., Fukunaga, M. \& Katsuyama, H. (2004) Effects of genetic and nutritional factors on bone mineral density in young adults. Int. J. Mol. Med., 14, 669-676.

Prynne, C.J., Mishra, G.D., O'Connell, M.A., Muniz, G., Laskey, M.A., Yan, L., Prentice, A. \& Ginty, F. (2006) Fruit and vegetable intakes and bone mineral status: a cross sectional study in 5 age and sex cohorts. Am. J. Clin. Nutr., 83, 1420-1428.

Sakamoto, H. \& Miyoshi, M. (2000) Factors affecting the stiffness index and its annual change in female subjects-relationship with menu choice and exercise duration. Eiyougaku Zasshi, 58, 5-14 (In Japanese).

Sawa, J., Fujii, T., Nishikawa, T., Fukatsu, C., Kannan, T., Musiaki, K., Shimizu, N. \& Yoshimoto, S. (2001) Effect of daily physical activities and dietary habits on the bone density of female college subjects. Eiyougaku Zasshi, 59, 285-293 (In Japanese).

Shea, M.K. \& Booth, S.L. (2008) Update on the role of vitamin K in skeletal health. Nutr. Rev., 66, 549-557.

Simon, J.A., Hudes, E.S. \& Perez-Perez, G.I. (2003) Relation of serum ascorbic acid to Helicobacter pylori serology in US adults: the Third National Health and Nutrition Examination Survey. J. Am. Coll. Nutr., 22, 283-289.

Tomita, N., Gushiken, M. \& Akisaka, M. (2004) A study on relationship between bone mineral density and dietary habits and lifestyle of junior college dietetics subjects. Kyouiku Igaku, 50, 87-97 (In Japanese).

Ueno, K., Nakamura, K., Nishiwaki, T., Saito, T., Okuda, Y. \& Yamamoto, M. (2005) Intakes of calcium and other nutrients related to bone health in Japanese female college students: a study using the duplicate portion sampling method. Tohoku $J$. Exp. Med., 206, 319-326.

Yokouchi, J., Ando, D., Ono, Y., Ozaki, Y, Asakawa, K., Kitagawa, J., Nakahara, Y. \& Koyama, K. (2006) Influence of anthropometric measures and lifestyle-related factors on the two-year changes of bone mass in college-aged women. Tairyoku Kagaku, 55, 331-340 (In Japanese). 